van Aalst, J., \& Chan, C. K K. (2012). Empowering students as knowledge builders. In L.

Rowan \& C. Bigum (Eds.), Transformative approaches to new technologies and student

diversity in futures oriented classrooms: Future proofing education (pp. 85-103). Dordrecht, the Netherlands: Springer Science + Business Media.

\title{
Empowering Students as Knowledge Builders
}

\author{
Jan van Aalst and Carol K.K. Chan
}

The University of Hong Kong

We discuss knowledge building in the context of government examinations in Hong Kong, and the need to develop 21st-century skills. Following this, we describe two pedagogical designs intended to develop knowledge building in this context: A gradual approach to develop it in four phases-developing a collaborative classroom culture, engaging in inquiry and curriculum adaptation, deepening knowledge-building discourse, and making use of knowledge-building principles and electronic portfolios - and an approach that extends from this to improve integration of the use of a web-based knowledge-building environment and classroom activities.

\section{Introduction}

'Knowledge building' refers to the practices by which the state of knowledge in a community is advanced. It exists throughout society-e.g., in scholarly communities, innovative corporations, clubs, online game communities, and artistic communities - but is rarely found in schools. One of its defining features is a shared goal within a community to extend the frontier of knowledge in that community. Scardamalia and Bereiter (2006) contrast it with 'learning', which they consider the passing of a community's intellectual heritage to the next generation. For example, the articulation of a contemporary interpretation of Hamlet, leading to a new production of Shakespeare's play, can be considered knowledge building, but the effort to understand an existing interpretation learning. In the first case a new intellectual artefact is created; in the second students become familiar with and internalize an intellectual artefact that preexisted, but is new to them.

The goal of this chapter, which appears in a book on future-proofing students for the 21 st century, is to examine the potential of knowledge building for addressing 21 st century educational needs. We do not believe that "proofing" students for a largely unknown future world is feasible, but are committed to the 
goals that underlie the proofing approach developed in this book, including: more student-centered and democratic learning environments; 21 st-century skills such as working together, ideation, and knowledge creation; increased student responsibility for their own learning; and the thoughtful use of IT to support learning. We agree with Collins and Halverson (2009) that the nature of schools must change to make better use of the potential of educational technology to address such needs. We relate knowledge building to 21 st-century skills, review the educational context in Hong Kong, and discuss our progress to implement knowledge building there.

\section{Knowledge building}

As an educational possibility, knowledge building is based on research on different forms of expertise, such as writing, problem solving, and playing chess. Many studies in the 1960s through 1980s showed that experts rely on vast amounts of domain knowledge and approach problem solving differently than novices. For example, chess players rely on knowledge of a vast collection of board patterns (de Groot 1965), and physics experts first analyze problems qualitatively to understand which physical principles are involved and then apply formulas, whereas novices directly apply formulas (Mestre 1991). From the vast literature on expert-novice comparisons, there would be little reason to think that children could be considered "expert-like" in their approaches to learning.

Knowledge building can be understood from a different type of comparison (Bereiter and Scardamalia 1993): between experts and people who, despite similar training and experience, have not become experts (experienced non-experts). This kind of comparison focuses on the approaches to learning that people who become experts use in their domains of expertise, rather than on expertise as an end state. Bereiter and Scardamalia found three major differences between experts and experienced non-experts: Experts were aware of the limits of knowledge in their fields; engaged in progressive problem solving, in which they reinvested cognitive resources into studying a problem at progressively deeper levels; and were committed to a shared goal to advance the state of knowledge in their fields. These authors proposed that although young children clearly have much less domain knowledge than experts, they could be considered expert-like if they already use these strategies. Their research program aims to facilitate the learning strategies of people on the career paths of experts in school. Their first software, computersupported intentional learning environments (CSILE), was designed to to help students maintain a focus on the use of writing to contruct knowledge rather than just transfer their ideas to written form. Its successor, Knowledge Forum, was first released in 1997 (see Figure 1 later in the chapter; Scardamalia 2004).

Early theoretical papers argued that teachers usually do much cognitive and meta-cognitive work that can be executed by students (Bereiter and Scardamalia 1987), and that educational activities were frequently not aligned with learning 
goals, so that learning was a by-product of activities rather than an intended goal (Bereiter and Scardamalia 1989). As Bereiter (1992) observed, in school projects such as building a model of a human lung, the model, rather than the desired understanding of the human lung, often becomes the outcome of the project. Thus, among the main pedagogical challenges for implementing knowledge building in school were: transfer of control over learning processes from the teacher to students, and a focus on understanding and idea improvement rather than task completion. Despite extensive research and theoretical and technological developments in the last two decades, these challenges have remained. In the 21st century, addressing these problems has become even more urgent than in the 1980s.

Brown and Campione (1996) observed that classroom implementations of innovative approaches are often reduced to procedures that distort the approach to such an extent that the principles that underlie it no longer are recognizable. Therefore, Scardamalia (2002) developed a system of 12 principles that describe the socio-cognitive and technological dynamics of knowledge building, which are employed to guide classroom work. In the next subsections we briefly discuss the six principles we consider most pertinent to our work.

\section{Improvable ideas}

The improvability of ideas is an epistemic point that draws from Popper's (1972) theory of objective knowledge: Ideas are improved by means of a public discourse of scrutiny, testing, and modification. In this respect, the ideas that students encounter in their formal education, such as Newton's theory, provide the most reliable explanations of phenomena, but may some day be challenged by new evidence, analyses, or ideas. Thus the work students do to "improve the quality, coherence, and utility of ideas" (Scardamalia 2002, p. 78) is epistemologically similar to knowledge creation in general.

The contribution of an idea to a public discourse is a creative act, and requires a psychologically safe environment. For example, students must feel that their ideas are taken seriously, that their social status in the class is not compromised if they contribute ideas, and that their ideas are not used inappropriately. In Canadian classrooms, we have observed that some students are reluctant to contribute an idea to Knowledge Forum for fear that other students will "copy" their idea (e.g., van Aalst and Hill 2006, p. 34). And, as one teacher noted, the notion of sharing ideas that are in some way inadequate runs counter to the culture of schooling: "...The name of the game in school is to keep [students' theories] hidden, not to bring them out in the open, not to ask in case it's a stupid one, not to write something down in case it's the wrong answer" (quoted in Hewitt 1996, p. 132). In Asian contexts these issues can be even more prominent, since students avoid "losing face" and students are often ranked within their class. 


\section{Epistemic agency}

According to the principle of epistemic agency, students "set forth their ideas and identify gaps in understanding; they deal with problems of goals, motivation, evaluation, and long-range planning that are normally left to teachers" (Scardamalia 2002, p. 79). This principle is crucial for empowering students to be in control of their own learning, which is required for lifelong learning.

An important aspect of epistemic agency is that students are aware of what they know and do not know. For example, they may be aware that there is much more to know about a topic than they currently know, and that their investigative work must therefore involve the study of external sources that are accessible to them. From this, students design and carry out investigations to advance from the community's collective knowledge. Epistemic agency also requires that students are able to judge when they have made acceptable progress. In this, they may check the overall scope and coherence of what they have come to understand and external requirements such as curriculum guidelines.

Epistemic agency relies on a wide range of 21st-century skills, including ability to identify and retrieve information in a variety of media, read for understanding, summarize what is known, and decide when it is time to review progress. Because these activities are complex and take place in a community, sophisticated social skills are also required, including ability to resolve disagreements, plan, monitor, and judge the merit of what has been accomplished. The teacher does not usually know the answers to all the questions that the students are investigating, but he or she should have expertise in the requisite skills and model them.

\section{Collective responsibility for community knowledge}

Students are members of a community, and work towards the shared goal to advance from what the community collectively knows (Scardamalia 2002). That students are members of a community implies that they feel a sense of belonging to the group, are willing to work with each other, and are helpful to one another. The emphasis on communal goals requires collaborative and cooperative skills that surpass those needed for most forms of learning in small groups. Clearly the teacher has an important role in cultivating these abilities, and may need to help the students when important ideas are ignored, some students are not contributing, or social conflicts develop. However, over time, students also fulfill this role.

In education, the emphasis on shared goals and accomplishments is controversial because educational success is measured almost entirely in terms of individual achievement. The teacher may need to persuade high-achieving students that a focus on shared goals can benefit them. Nevertheless, outside of school adolescents are attuned to learning in communities including gaming communities, clubs, and online communities such as YouTube and Facebook 
(Collins and Halverson 2009). Communities provide authentic contexts for learning that build on students' interests. Research in education is increasingly giving attention to learning in informal settings, including in authentic communities. For example, Roth and Lee (2004) investigated how middle school students contributed to the knowledge base of a local creek.

\section{Democratizing knowledge}

Scardamalia (2002) defines democratizing knowledge as follows: "All [students] are legitimate contributors to the shared goals of the community; all take pride in the knowledge advances achieved by the group" (p. 80). Knowledge Forum is an online knowledge base to which all students can potentially contribute. In contrast, relatively few students can contribute to any whole-class face-to-face discussion (Hoadley and Linn 2000). Teachers who collaborate with us have often observed that some students who are silent in class are prolific writers in Knowledge Forum. The relative anonymity of asynchronous discussion, which does not require the simultaneous attention of other students in the class, seems to provide additional psychological safety that enables students to make contributions. Effort by teachers and students to focus on idea improvement, rather than the person who contributes an idea, also enhances this safety.

Although all students contribute to the work of the community, they may do so in different ways. In the 1990s, some students in an inner city school had limited writing skills in English and wrote notes in Spanish; other students translated these notes to render them more accessible to the community. More recently, children in the earliest grades of elementary school enter notes for children who have not yet developed the requisite skills. These approaches make it possible for students with varied literacy levels to contribute their ideas.

\section{Knowledge-building discourse and embedded and transformative assessment}

Bereiter (2002) argues that the knowledge of a community is reified in its conceptual artefacts - its proofs, theories, ideas, and explanations - and that these are improved by means of public discourse. Knowledge building exists in its discourse. However, the discourse must be oriented toward the advancement of the community's collective knowledge. An experiment is not just motivated by a scientist's own curiosity, but by its potential for illuminating gaps of knowledge in the community. New investigative methods are developed when the community feels that it can no longer make progress with existing methods. Thus, part of the discourse involves the review and synthesis of progress. 
The discourse is progressive in the sense that it builds on what is already known and advances lead to new questions and ideas. There are emerging lines of inquiry that were not anticipated at the outset. This situation can be contrasted with linear inquiries that stop once an answer to the initial question has been found, such as the 5E model of inquiry (Bybee et al. 2006) that is commonly used in K-12 education. However, outside of school it is common: A student may seek to play and understand a video game at continuously more advanced levels (Gee 2007).

The major implication of knowledge-building discourse for education is that it is cognitively more demanding than the discourse by which students typically learn in school. Knowledge builders cannot look up the correct answer in the back of the book, but must devise other methods to become confident that a knowledge advance has taken place. We believe that most uses of online forums in education do not currently reach the level of discourse that is required for knowledge building (Scardamalia and Bereiter 2006; van Aalst 2006, 2009). Therefore, the principle of embedded and transformative assessment is used to support the enhancement of knowledge-building discourse. As part of their knowledgebuilding efforts, students self-assess their progress and evidence of the knowledge-building principles in their discourse, and take steps to enhance these. Current research is developing tools that visualize online discourse to render such assessment more feasible in typical classrooms (Teplovs 2010).

\section{Addressing the needs of diverse learners through knowledge building}

As a community-oriented practice, knowledge building takes advantage of the diversity of interests, knowledge, and abilities within classrooms. There are opportunities for all students to make valuable contributions, learn from others, and develop their interests. And although no large-scale studies are available and students with high prior achievement generally outperform students with low achievement, the literature suggests that students across ability levels are able to participate in and benefit from knowledge building. For example, Niu and van Aalst (2009) compared the performance of students in a mainstream and an honors version of a Grade 10 social studies course; they examined alignment between the discourse and knowledge-building principles and domain knowledge in a postexperience portfolio. They found that the discourses in the two courses were similar from the point of view of the knowledge-building principles, but that on the portfolios students in the honors course outperformed those in the mainstream course - to a degree consistent with their higher prior achievement (approximately 20\%). Our other studies show similar effects (van Aalst and Chan 2007). Relatively small variation in posttest scores in some studies also indicates that the insights gained by a few students are widely diffused (Zhang et al. 2007). 
It is worth noting that while the usual argument for knowledge building is primarily cognitive, one could also argue for it from the perspective of addressing the needs of students disenfranchised with school. For example, Banks (2008) points out that due to globalization, diversity is increasing dramatically in classrooms in many countries. He argues that young people need to be prepared for "transformative citizenship": citizenship that enables them to go beyond the values and moral principles of existing society to change society. This view is very consistent with that of knowledge building, which emphasizes advancement of the frontier of knowledge (Scardamalia 2002).

In the following vignette we describe briefly how a an at-risk student, as a result of his work on Knowledge Forum, became interested in writing, and entered and won a regional writing competition. Though the extent of what was accomplished in this example can be overstated, the introduction of Knowledge Forum seems to have provided the student a way to become more engaged with his education, and socially more accepted.

Vignette 1: Knowledge Building at a Band-3 School: "James"

\begin{abstract}
James was a Form 4 (Grade 10) student from secondary school that enrolled the academically weakest students in Hong Kong; its students were around the 10th percentile on a standardized placement test. Such schools provide their students poor access to tertiary education and white-collar jobs. Students frequently are unmotivated, and relatively few graduate. However, some of James' teachers became interested in knowledge building, and hoped that it might offer their school a way to get students more interested in their education.

James had been an isolated and silent student for years, and his teachers thought that he had several learning disabilities; he did not seem able to make many useful contributions during class activities. But when one of his teachers used Knowledge Forum, James began writing quite a few notes. He said that he liked it because he had more time to think about his ideas before writing them than he would have in class. The teacher and James' classmates considered his ideas valuable, and James gained more respect among his peers. James became very interested in writing, and through the encouragement of his teacher began to improve his writing. He entered an inter-school writing competition - and won!
\end{abstract}

\title{
Chinese learners and educational reforms in Hong Kong
}

The work described in the remainder of the chapter focuses on our efforts to implement knowledge building in public schools in Hong Kong. This work is possible in part because of the close alignment between knowledge building and the 21 st-century skills that underlie a major curriculum reform, thus in this section we discuss the current educational context in Hong Kong. Specifically, we examine the cultural roots of government examinations and curriculum reforms since the beginning of the 21 st century. 
For more than two millennia, Chinese society was shaped by the teachings of Confucius, and the system of civil examinations inspired by them. The civil examinations endured from the Han dynasty (206-220 AD) till 1905. Throughout most of this period, they were used to select men from all walks of life for civil service positions, which came with prestige and social status. The underlying ideal was that all men could prepare themselves for the examinations and had access to government positions, regardless of their social class or family history. (Women were excluded throughout the period.) Preparing for all the examinations required many years of effort and commitment, but this was believed to lead to the moral self-perfection desired of those in government office. Han (1946) suggests, "the discipline was so thorough that those who succeeded in passing the examinations were looked upon with a respect that amounted to reverence" (p. 158).

The civil examinations were reformed frequently. For example, in the 11th century the examinations changed dramatically under the influence of NeoConfucianism, a philosophical movement drawing from Taoism and Buddhism and providing a conceptual basis for the teachings of Confucius. Among NeoConfucian concepts were $l i$ (understanding, coherence) and xin (mind). Whereas in the Tang dynasty the "meaning" of the Classics entailed knowing to what their words pointed, but 11th century intellectuals saw a role for the mind, which was "capable of grasping the patterns, principles, commonalities, and systems that underlay what was manifest ... in the texts" (Bol 2008, p. 66). This opened up the possibility of interpreting the Classics to illuminate policy problems of the day, and was closer to the Confucius' teachings emphasizing thinking for oneself and inquiry. In time, Neo-Confucianism became the curriculum, and examination candidates were expected write essays in which they reasoned about policy issues of current interest. From a modern perspective, we might call the underlying learning theory constructivist. It could even be argued that candidates were building knowledge.

However, in the Qing dynasty (1644-1912), the civil examination system gradually failed for two main reasons (Elman 2000). (1) It could not be scaled up. As participation increased, examiners were no longer able to read essays closely and focused on conformity with the requirements of the "eight-legged essay" rather than the big ideas of the candidates; in addition, the examinations became extremely competitive and no longer provided the possibility of upward social mobility to commoners (Elman 2000). Over time, dissatisfaction grew among intellectuals concerning the adequacy of the civil examinations for selecting the most talented men for civil service. (2) In the 19th century, influences from the West and social unrest also increased. By the first two decades of the 20th century, the dynastic system, the civil examinations that supported it, and the dominance of Confucian thought all ended.

The transition to new models is still incomplete (Chan 2009). The civil examinations provide the foundation for the rigor and competitiveness of the current government examination system, and Confucian values such as effort and moral and social development continue to influence how students, teachers, and parents think about learning and education. For example, research on conceptions 
of learning of college students of Chinese and European descent shows that the former have conceptions of learning that refer to hard work, moral development, and "heart and mind to learn"; when such students fail they attribute it to a lack of effort rather than a lack of ability (Li 2002, 2009). In a study of management issues in science classes in China, Israel, and Australia, Lewis et al. (2005) found that Chinese teachers were more likely to mention that "learning to respect authority was a significant outcome of education" (p. 731). In Hong Kong, results on the Hong Kong Certificate of Education Examination are used to select students for Advanced Level courses. These examination results thus have important consequences for students, teachers, and school administrators, and teachers are reluctant to employ methods that may compromise them (Gao and Watkins 2002; Wu and Huang 2007). In Hong Kong, parents of all social classes invest much effort into enrolling their children in a good school and supporting teachers (e.g., making sure that homework is done); many parents who can afford it may send their children abroad to continue their education in a less competitive environment after the HKCEE. Nevertheless, East-Asian educational systems have consistently led to strong performances on international comparisons of achievement, particularly in mathematics and science (Stigler and Hiebert 1999). All of these effects constrain the extent to which a Western approach like knowledge building can be implemented in East-Asian contexts.

East-Asian governments have realized that new approaches are needed for the 21 st century, in which sustained innovation and knowledge creation are important capabilities. As a result, the Hong Kong government has invested more than a decade in preparing for a major reform of the secondary school curriculum. This reform includes emphasis on learning how to learn, student-led inquiry, projectbased learning, reading to learn, and school-based assessment (CDC 2001; CDC/HKEAA 2007). The New Secondary School (NSS) curriculum launched in 2009 reduces secondary school from four years to three, and will increase the length of undergraduate university education from three to four years by 2012. It also has introduced a new core subject, Liberal Studies, in which students are expected to use their knowledge learned from other subjects to articulate positions on complex societal problems; developing understanding of multiple perspectives on a problem and argumentation are key capabilities to be developed by this subject. The NSS is based on decades of research on how people learn and changing views about the roles and nature of assessment.

We expect that pedagogical practices based on the NSS curriculum need to be more structured than most Western examples of constructivist learning, but take advantage of effective collaborative and reflective learning strategies that lead to understanding of domain knowledge and higher-order thinking. We believe that if the NSS is successful, it will lead to pedagogical innovations that advance not only on existing practices in Asian countries but also in Western ones. 


\section{Progress towards knowledge building in Hong Kong}

Since 1996, much effort has been invested globally in the development of an international community of teachers and researchers. The goal of this community is to build synergies between local teams for developing and sharing pedagogical designs and research; the community meets annually for a summer institute at the Institute for Knowledge Innovation and Technology (IKIT, www.ikit.org), and has organized several international collaborations. In Hong Kong, we have co-led the Knowledge Building Teacher Network (KBTN, kbtn.cite.hku.hk) with Nancy Law since 2006; it currently involves more than 60 teachers from 25 schools. The KBTN employs a mentoring scheme in which teachers who have implemented knowledge building in their own classrooms hold 50\% seconded positions at the KBTN and lead professional development activities for the remaining teachers, including workshops, collaborative pedagogical design, and classroom observations. In the next subsections, we describe the main pedagogical designs developed by the KBTN. Both of these models exemplify how teachers in Hong Kong interpret and adapt knowledge building in terms of local constraints, especially the importance of government examinations.

\section{Implementation path with knowledge-building portfolios}

Knowledge building was first implemented in Hong Kong classrooms in 2000. Over the years, researchers and teachers have developed a pedagogical model and classroom design that aim to remain faithful to the spirit of knowledge building, but attend to the contextual dynamics in Hong Kong that we described earlier. The following four-phase implementation path has been employed in Hong Kong in a variety of subjects (Geography, Chemistry, and Chinese) and at grade levels ranging from Grade 8 (diverse abilities) to Grade 12 (advanced courses). We have found the outcomes of this approach to be consistently encouraging in these classrooms (Lee et al. 2006; van Aalst and Chan 2007).

\section{Phase 1: Develop a collaborative classroom culture.}

Chinese classrooms are not attuned to knowledge construction and collaboration. Teachers see their roles as explaining difficult material clearly and preparing students for examinations, and students do not like to discuss their ideas publicly before they are confident about them (Gao and Watkins 2002; Li 2009). Therefore, KBTN teachers like to spend several months creating a learning environment in which it is safe to share and discuss ideas, but in which activities are oriented toward understanding - before they introduce Knowledge Forum. For this, they introduce students to effective cognitively oriented learning strategies. 
Some teachers implement concept mapping as a strategy for determining what students in a small group understand about a topic; teachers of Chinese use reciprocal teaching (Palincsar and Brown 1984) extensively in the context of reading to learn, which is an important "key task" in the NSS curriculum (CDC 2001).

During this phase activities are highly structured, but they cultivate social interaction in small groups that is oriented toward understanding subject knowledge, and they cultivate competence in the use of cognitive tools such as concept mapping and reciprocal teaching. This blending of social interaction and cognition is not always evident in Western classrooms. In our earlier work involving Canadian teachers, some teachers were very interested in having students work together, but were reluctant to teach them the skills students needed to make it effective. The teachers were very concerned with developing a sense of community among their rather unmotivated students, but it was not the kind of community that works to improve knowledge. A study of Australian and Taiwanese students found that Australian students tended to focus on the quality of social interactions, and Taiwanese students more on the learning goals underlying the task (Aldridge and Fraser 2000).

\section{Phase 2: Inquiry and curriculum adaptation.}

Although Phase 1 orients the learning environment towards collaboration and knowledge construction, it does not yet accomplish some important changes that are required for knowledge building: The teacher mostly remains in control of the learning goals and tasks. In Phase 2, students begin to use their learning experiences during class as a foundation to articulate and investigate shared problems of understanding. Due to time constraints and emphasis on examinations, teachers in Hong Kong are reluctant to use class time for work on Knowledge Forum but assign it as homework: Standard exercises are replaced by student-to-student interactions.

The key goal of the pedagogical design here is to utilize the skills developed in Phase 1, and frame students' work in Knowledge Forum in such a way that shared problems of understanding emerge from their discourse, and that there is room for these to be investigated. Thus, the learning environment becomes more community oriented, the learning goals become emergent and authentic to the students, and agency over the educational process is substantially turned over to the students. Although the learning goals and what students will learn are not known in detail at the outset, students are individually and collectively accountable for what they learn, and the skills learned in Phase 1 help to keep students' work on Knowledge Forum oriented toward advancement of the class's knowledge.

For example, in a Form 3 (Grade 9) Chinese Culture course, the teacher asked students to start by exploring their thoughts about the school rules, a topic of considerable interest to middle-school students. This strategy was innovative because it encouraged students to express views and inquire into authentic 
problems. In Hong Kong, students are required to follow many rules, such as the permissible length of the school uniform. The teacher encouraged students to work on problems that held their interest, and helped them to advance from these to the principles that underlie school rules, and notions of freedom and choice; this was then connected to the teachings of the Classics. The ensuing discussion on Knowledge Forum led to an investigation into notions of "rules of propriety and rituals" $l i$ (禮), central philosophical concepts in Chinese culture. Students utilized progressive discourse on Knowledge Forum to deepen their understanding, and examined their beliefs and values related to Chinese philosophies and culture. They were asked to interpret Chinese classical texts from Confucius to contemporary authors and newspaper readings students chose for themselves. This teacher blended structure and openness through knowledge building. Students investigated their own questions and ideas, but were expected to make constructive use of authoritative sources (Scardamalia 2002), taking reading-tolearn strategies developed in Phase 1 online. The teacher required regular contributions to Knowledge Forum from all students and monitored their progress. This course was a mandatory course for all students at the school, hence involved a more diverse student population than our work in more advanced and elective courses.

Other KBTN teachers have used similar approaches for other subjects. For example, students in a Grade 12 Geography course used Knowledge Forum to investigate problems of understanding concerning plate tectonics that remained after classroom teaching (van Aalst and Chan 2007). Work on Knowledge Forum led to the integration of ideas discussed in class, supported by examples and elaborations, and led to a more comprehensive understanding of the topic that was shared by most students in the class. Students pursued their own interests and emergent questions, but in doing this they kept the examination syllabus in focus when deciding whether a problem merited additional effort. Students discussed relationships among plate tectonics, continental drift, and seafloor spreading in detail because explaining these relationships was considered important to understanding of plate tectonics. Interviews showed that students used Knowledge Forum to develop their understanding of domain knowledge for the examination. Some students said that when they wrote on Knowledge Forum, they needed to understand the contributions of their peers, and that this led them to study more and enhance their own understanding; they also said that the ideas of others provided them a broader perspective on the topic under study.

\section{Phase 3: Deepening knowledge-building discourse.}

After students have worked on Knowledge Forum for one to two months, teachers initiate activities that help students to reflect on and improve their discourse, and that improve the integration of work on Knowledge Forum with classroom events. Thus, they bring the principle of embedded and transformative assessment into focus. 
Some teachers institute "KB talks," which are whole-class face-to-face conversations about the database that help students to gain an overview of progress, set new goals, and solve problems that do not require extensive discussion (Zhang et al. 2007). Teachers in the network vary regarding the time they devote to KB talks; however, the more progressive teachers see this as crucial for the articulation of emerging questions and ideas. They devote attention to showing that students of diverse abilities and backgrounds can contribute to the collective progress - even a superficial question can bring about much interest, and the teachers acknowledge such contributions during KB talks.

Many teachers also begin to use analysis tools that provide information about participation rates and the social structure of the online discourse. Knowledge Forum includes assessment tools that allow teachers to detect easily whether all students are contributing notes, are reading a substantial number of notes, and have at least several collaborative partners who read and build onto their ideas. Teachers in Hong Kong are eager to use such tools to gain an understanding of how the class is progressing. Although the analyses tend to be initiated by the teacher, the tools are designed so that students can eventually use them independently. As shown in Figure 1, teachers may also ask students to moderate specific discussions, and teach the use of advanced features of Knowledge Forum that students can use to enhance their discourse. van Aalst (2009) has shown that without explicit attention to advanced tools, the use of Knowledge Forum may settle at a rudimentary level, at which students write and respond to notes, but do not synthesize what is being learned and what merits further investigation or discussion. Especially if students are pursuing emergent goals, it is important that their advances accomplished in Knowledge Forum are easily identifiable. 


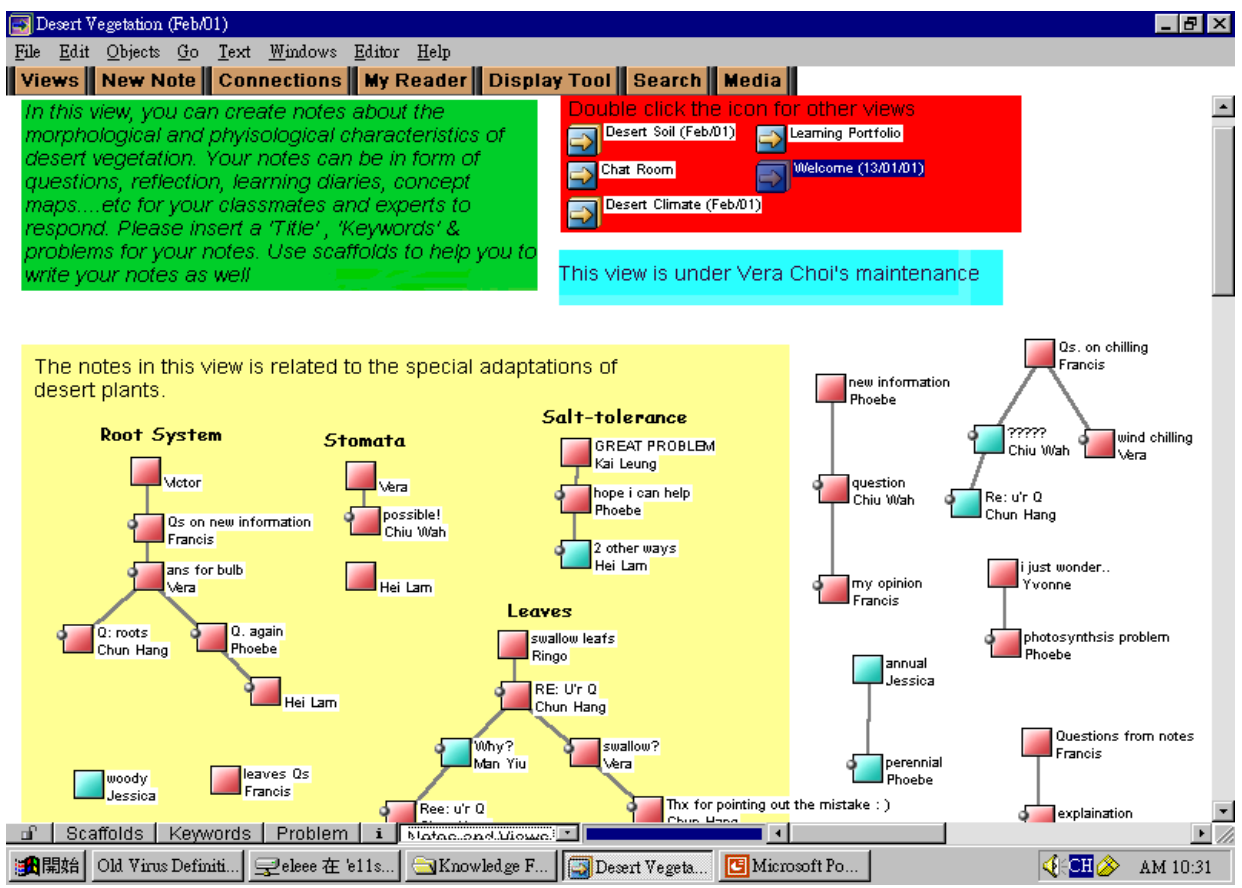

Figure 1. Section of a view (a shared workspace) in Knowledge Forum. Notes are represented by square icons (dark if they have been opened by the user, and lighter if not.) A line between notes indicates that one note is a response to the other. Notes can be moved around in the view, and drawings can be embedded in the view background to provide organization (conceptual or otherwise). This view was maintained by a student.

\section{Phase 4: Knowledge-building principles and electronic portfolios.}

After students have used Knowledge Forum for some time, the knowledgebuilding principles are introduced; these provide a technical vocabulary that students can use to understand what they have been doing on Knowledge Forum. For example, students often spontaneously identify the diversity of ideas as a benefit of discussions on Knowledge Forum, and note that some students who had remained silent during class contribute to Knowledge Forum. The knowledgebuilding principles make sense to students when they are introduced to them at this stage.

Once students are familiar with the principles, some teachers ask them to use them to self-analyze the class's discourse. Although there are considerable variations in design, one approach is to ask students to select clusters of notes they considered useful, and discuss the extent to which they show evidence of several of the principles. Students write up their analysis in a "portfolio note" in Knowledge Forum, which has hyperlinks to the notes in the clusters. We have 
reported empirical studies of these portfolio notes elsewhere (Lee et al. 2006; van Aalst and Chan 2007). We found that portfolio note scores predicted conceptual knowledge over and above depth of explanation and depth of inquiry, and students said in interviews that preparing the portfolios helped them understand how to improve their future contributions to Knowledge Forum. Lee et al. (2006) found that the use of principle-based portfolios enhanced depth of inquiry more than portfolios in which students did not use the principles.

Phase 4 completes the trajectory by providing a more conceptual basis for students' analysis of online discourse than was possible in Phase 3 . We believe this kind of experience is important if students are to understand the dynamics of knowledge building.

\section{Enhancing the integration of technology use and classroom events}

The foregoing implementation path has several important advantages. It is a gradual approach, in which teachers first implement or enhance collaborative and cognitive strategies to improve learning, and later initiate students into a reflective practice that involves the use of Knowledge Forum, learning the knowledgebuilding principles, and assessments of online discourse. The gradual implementation seems necessary in Hong Kong's education culture with its emphasis on competitive examinations that test comprehensive knowledge and understanding. Without a gradual implementation path, discussions can be unfocused and unproductive (Kirschner, Sweller, and Clark 2006). With it, the database can be a communal memory of what the community has come to understand - and a resource for consolidating understanding when the class approaches its examination.

However, this implementation path does not go sufficiently far in opening possibilities for emergent learning goals, epistemic agency, work on problems that are authentic to students, and progressive inquiry. As a result, teachers have difficulty fully incorporating knowledge building into their classroom practice. Among the main difficulties are the nature of classroom discourse and the framing of work on Knowledge Forum. Therefore we are studying how teachers who have more experience with Knowledge Forum may enact a comprehensive pedagogy that is more clearly oriented toward knowledge building. We first provide a vignette of such a teacher's classroom practice, and then discuss the issues arising from it.

Vignette 2: The Physics Lab at Charles K Kao Secondary School

The 41 students in the Grade 10 Physics class sit in groups of six or seven around large lab tables. In these groups they do many things such as conduct brief experiments, discuss results and questions, and solve short tasks. There are cheers and sometimes applause. There is a lot of motion. Students walk up to the blackboard to explain a point to their peers. We also find students working at the blackboard before explaining, with the teacher 
some distance away. We find the teacher helping the students (e.g., passing materials to them). Sometimes the teacher can be found at the students' elbows, thinking about what is going on with them. And sometimes the teacher just sits for a moment at a table with the students. Though there is always much to do, the pace never feels rushed. The students look relaxed and happy to be doing physics. There are few management problems. Though the class size is large, the lab does not feel crowded.

The teacher uses the experiments from the textbook, but often considers the full experiment too laborious to keep the students engaged and interested. Therefore, a specific group of students will often complete just one part (e.g. varying the mass but not the force in a Newton's Second Law experiment). Different groups then complete different parts, and two members from each group are called upon to share their findings with the class at the blackboard. When some students are not satisfied with an explanation there may be laughter but it is never demeaning. For example, after two students had explained to the class how a sea breeze arises at a beach, one student asked whether this application applied for daytime or night. When the students said, "I don't know," there was laughter, but other students and the teacher then helped to develop a more satisfying explanation. The teacher allowed the time she had planned for students to provide their explanation ( 2 minutes) to expand to more than 10 minutes, to allow students to think through the problem. In examples like this, where many ideas are proposed and progress is slow, the teacher does recap and teach the correct explanation, but it is an explanation that has at least partly been articulated by the students. The main purpose of doing this is to ensure that students remember the best explanation, rather than a minor point that was made along the way.

The blackboard is a space that belongs to the class, rather than the teacher alone. The teacher usually provides a very brief introduction to a short activity and provides students an issue to think about during their experiments. For example, introducing a quick "exploding carts" experiment that all the groups did with data-logging equipment, she asked students: "Where does the kinetic energy come from?" After the experiment a question then arose, in which a student recalled that in an earlier (free fall) experiment the velocity was independent of the mass, but in the current experiment it was not. As in the example involving the sea breeze, this question lead to an extended discussion.

Although the classroom discussions are focused on ideas and explanations, they are fixed in time, and are not later available for retrospection.

This vignette is intended to suggest that the learning environment is a community in which students have fun, care for each other, and are focused on learning physics. Small-group activities are not just activities to be completed, but set the stage for thinking about scientific phenomena. The class's discourse focuses on explanations in terms of causes and effects. In having students provide explanations to each other, the teacher is developing a cognitive strategy-selfand peer explanation - that is known to lead to deep knowledge in science (Bielaczyc, Pirolli, and Brown 1995). Although student ideas form the basis of the class's discourse, the blackboard has remained a focal point in the classroom: After their initial work in class groups, students are explaining to the whole class.

We have collected extensive data in this classroom focusing on attitudes toward science, epistemological beliefs, performance on explanation and problem-solving tasks, and conceptual surveys. Results indicate that students had more positive attitudes toward science than in comparison classes, made acceptable progress toward conceptual change, and raised conceptual questions about lesson material.

The teacher developed the social practice of peer explanation to the class in approximately one month, in quite a structured way. At the beginning of the 
school year, students prepared their explanations in small groups, and two students from each group were called to make a 2-minute presentation of their explanation. Over time, it became a more dialogic process, in which the teacher had her eyes open for opportunities for students to come to the blackboard. In a few months the students became very comfortable with this practice and accepted it as normal.

However, the creation of this kind of learning environment is difficult. The teacher had two abilities that made it possible: She was able to identify what Viennot (2003) calls the "critical details" involved in understanding physics topics, and through her questioning and task design she was able to focus students' thought on those critical details. We regularly observed a second teacher at the same school, who had excellent command of the critical details and provided superior explanations to students, but was uncomfortable with allowing students sufficient time and space to struggle with them on their own. A third teacher also had excellent grasp of the critical details, but was not quite able to orient questioning and tasks toward them; he rather tended to focus on the procedures involved in tasks.

The foregoing discussion shows that two issues are crucial to the implementation of knowledge building. First, teachers need to learn how to facilitate classroom discourse that is focused on ideas and explanations. Second, this discourse is likely to be constrained significantly by limitations on instructional time. We have concluded that it is impossible to adequately address the second issue without making the use of educational technology central to classroom activities. Therefore, we have outfitted the lab with an interactive whiteboard (IWB) and a laptop computer for each small group of students. The IWB makes it possible to save the diagrams and notes from student presentations in Knowledge Forum, and also to access Knowledge Forum, the Web, and computer tools and files such as results from experiments. Students use the laptops to review recent work on Knowledge Forum in their groups, often in preparation for class presentations. Our initial experiences suggest these tools provide a more seamless knowledge-building environment, which makes linkages between online and offline discourse less artificial. In current work in this classroom, we are exploring how to optimize the balance between face-to-face work and work on Knowledge Forum.

\section{Summary}

This chapter has provided a general overview of knowledge building as an approach to fostering 21 st-century skills-particularly for East-Asian students. We discussed knowledge building in terms of knowledge-building principles (Scardamalia 2002). Idea improvement and collective responsibility for community knowledge define the overall goals toward which knowledge building is oriented, and knowledge-building discourse is how it is accomplished-the knowledge building is in the discourse. Epistemic agency and embedded and 
transformative assessment refer to two general sets of responsibilities that students have in knowledge-building communities, but that are currently in the domain of teacher actions. Democratization of knowledge identifies another goal: that students are empowered to deal with their own needs for knowledge. Then we discussed the significance of government examinations in Hong Kong (and China generally), and their impact on classrooms, and described two pedagogical designs to support knowledge building in this context.

In the four-phase implementation path teachers begin by enhancing aspects of teaching and learning that are not specific to knowledge building but that help to create a social and academic environment in which it can develop. From Phase 2, teachers implement knowledge building and learn the tools and concepts for reflecting and improving their practice. Although this implementation path provides a framework for implementing knowledge building, we do not think that it-by itself - can go far enough in helping teachers transform their pedagogy. The second approach that we described requires a more comprehensive investment in knowledge building, in which discourse in Knowledge Forum can be integrated more fully with daily classroom events. Although this technology-rich environment has not yet been fully enacted, we believe that it is essential to making knowledge building the focus of a class's efforts.

\section{Acknowledgements}

The Knowledge Building Teacher Network (KBTN) is funded by a University-School Partnership grant from the Hong Kong Education Bureau and a General Research Fund grant from the University Grants Council (Grant HKU 740809). We gratefully acknowledge the contributions of all the teachers and students of the KBTN, Nancy Law, and the support staff of the Centre for Information Technology in Education of the Faculty of Education, the University of Hong Kong. Preparation of this chapter was supported by the Sciences of Learning Strategic Research Theme of the University of Hong Kong (Grant 1028665).

\section{References}

Aldridge, J. M., \& Fraser, B. J. (2000). A cross-cultural study of classroom learning environments in Australia and Taiwan. Learning environments Research, 3, 101-134.

Banks, J.A. (2008). Diversity, group identity, and citizenship education in a global age. Educational Researcher, 37, 129-139.

Bereiter, C. (1992). Referent-centered and problem-centered knowledge: Elements of an educational epistemology. Interchange, 23(4), 337-361.

Bereiter, C. (2002). Education and mind in the knowledge age. Mahwah, NJ: Lawrence Erlbaum Associates.

Bereiter, C., \& Scardamalia, M. (1987). An attainable version of high literacy: Approaches to teaching higher-order skills in reading and writing. Curriculum Inquiry, 17(1), 9-30. 
Bereiter, C., \& Scardamalia, M. (1989). Intentional learning as a goal of instruction. In L. B. Resnick (Ed.), Knowing, learning and instruction: Essays in honour of Robert Glaser (pp. 361-392). Hillsdale, NJ: Lawrence Erlbaum Associates.

Bereiter, C., \& Scardamalia, M. (1993). Surpassing ourselves: An inquiry into the nature and implications of expertise. Chicago, IL: Open Court.

Bielaczyc, K., Pirolli, P. L., \& Brown, A. L. (1995). Training in self-explanation and selfregulation strategies: investigating the effects of knowledge acquisition activities on problem solving. Cognition and Instruction, 13, 221-252.

Bol, P. K. (2008). Neo-Confucianism in history. Cambridge, MA: Harvard University Press.

Brown, A. L., \& Campione, J. C. (1996). Psychological theory and the design of innovative learning environments: On procedures, principles, and systems. In L. Schauble \& R. Glaser (Eds.), Innovations in leaning: New environments for education (pp. 289-325). Mahwah, NJ: Lawrence Erlbaum Associates.

Bybee, R. W., Taylor, J. A., Gardner, A., van Scotter, P., Carlson Powel, J., Westbrook, A., et al. (2006). The BSCS 5E instructional model: Origins, effectiveness, and applications. Colorado Springs, CO: BSCS.

CDC. (2001). Learning to learn - the way forward in curriculum (Report). Hong Kong, SAR, China: Government Printer.

CDC/HKEAA. (2007). Liberal studies curriculum and assessment guide (Secondary 4-6). Hong Kong, SAR, China: Curriculum Development Council and the Hong Kong Examinations and Assessment Authority.

Chan, C. K. K. (2009). Classroom innovation for the Chinese learner: Transcending dichotomies and transforming pedagogy. In C. K. K. Chan \& A. N. Rao (Eds.), Revisitiing the Chinese learner: Changing contexts, changing education (pp. 169-210). Hong Kong, SAR, China: CERC/Springer.

Collins, A., \& Halverson, R. (2009). Rethinking education in the age of technology: The digital revolution and the schools. New York: Teachers College Press.

de Groot, A. D. (1965). Thought and choice in chess. The Hague, the Netherlands: Mouton.

Elman, B. A. (2000). A cultural history of civil examinations in late imperial China. Los Angeles, CA: University of California Press.

Gao, L., \& Watkins, D. A. (2002). Conceptions of Teaching Held by School Science Teachers in P.R. China: Identification and Cross-Cultural Comparisons. International Journal of Science Education, 24, 61-79.

Gee, J. P. (2007). What video games have to teach us about learning and literacy (revised and updated). New York, NY: Palgrave Macmillan.

Han, Y.S. (1946). The Chinese civil service: Yesterday and today. Pacific Historical Review, 15, 158-170.

Hewitt, J. (1996). Progress toward a knowledge-building community. Unpublished doctoral dissertation, University of Toronto, Toronto, ON, Canada.

Hoadley, C. M., \& Linn, M. C. (2000). Teaching science through online, peer discussions: SpeakEasy in the Knowledge Integration Environment. International Journal of Science Education, 22, 839-857.

Kirschner, P. A., Sweller, J., \& Clark, R. E. (2006). Why minimal guidance during instruction does not work: An analysis of the failure of constructivist, discovery, problem-based, experiential, and inquiry-based teaching. Educational Psychologist, 41(2), 75-86

Lee, E. Y. C., Chan, C. K. K., \& van Aalst, J. (2006). Students assessing their own collaborative knowlegde building. International Journal of Computer-Supported Collaborative Learning, 1, 277-307. 
Lewis, R., Romi, S., Qui, X., \& Katz, Y. J. (2005). Teachers' classroom discipline and student misbehavior in Australia, China and Israel. Teaching and Teacher Education, $21,729-741$.

Li, J. (2002). A cultural model of learning: Chinese "heart and mind for wanting to learn". Journal of Cross-Cultural Psychology, 33, 248-269.

Li, J. (2009). Learning to self-perfect: Chinese beliefs about learning. In C. K. K. Chan \& N. Rao (Eds.), Revisiting the Chinese learner: Changing contexts, changing education (pp. 35-69). Hong Kong: Springer/Comparative Education Research Centre.

Mestre, J. (1991). Learning and instruction in pre-college physical science. Physics Today, 44(9), 56-62.

Niu, H., \& van Aalst, J. (2009). Participation in knowledge-building discourse: An analysis of online discussions in mainstream and honours social studies courses. Canadian Journal of Learning and Technology/La Revue Canadienne de l'Apprentissage et de la Technologie [online], 35(1). Retrieved from http://www.cjlt.ca/index.php/cjlt/article/view/515/245.

Palincsar, A. S., \& Brown, A. L. (1984). Reciprocal teaching of comprehension-fostering and comprehension-monitoring strategies. Cognition and Instruction, 1, 117-175.

Popper, K. R. (1972). Objective knowledge: An evolutionary approach. Oxford, UK: Clarendon Press.

Roth, W. M., \& Lee, S. (2004). Science education as/for participation in the community. Science Education, 88, 263-291.

Scardamalia, M. (2002). Collective cognitive responsibility for the advancement of knowledge. In B. Smith (Ed.), Liberal education in a knowledge society (pp. 67-98). Chicago, IL: Open Court.

Scardamalia, M. (2004). CSILE/Knowledge Forum ${ }^{\circledR}$. In A. Kovalchick \& K. Dawson (Eds.), Education and technology: An encyclopedia (pp. 183-192). Santa Barbara, CA: ABC-CLIO.

Scardamalia, M., \& Bereiter, C. (2006). Knowledge building: Theory, pedagogy, and technology. In R. K. Sawyer (Ed.), The Cambridge handbook of the learning sciences (pp. 97-115). New York, NY: Cambridge University Press.

Stigler, J. W., \& Hiebert, J. (1999). The Teaching Gap: Best Ideas from the World's Teachers for Improving Education in the Classroom. New York, NY: The Free Press.

Teplovs, C. (2010). Visualization of knowledge spaces to enable concurrent, embedded and transformative input to knowledge building processes. Unpublished doctoral dissertation, University of Toronto, Toronto, Canada.

van Aalst, J. (2006). Rethinking the nature of online work in asynchronous learning networks. British Journal of Educational Technology, 37, 279-288.

van Aalst, J. (2009). Distinguishing knowledge sharing, construction, and creation discourses. International Journal of Computer-Supported Collaborative Learning, 4, 259-288.

van Aalst, J., \& Chan, C. K. K. (2007). Student-directed assessment of knowledge building using electronic portfolios. The Journal of the Learning Sciences, 16, 175-220.

van Aalst, J., \& Hill, C. M. (2006). Activity theory as a framework for analysing knowledge building. Learning Environments Research, 9, 23-44.

Viennot, L. (2003). Teaching physics. Dordrecht, the Netherlands: Kluwer Academic Publishers.

Wu, H.-K., \& Huang, Y.-L. (2007). Ninth-grade student engagement in teacher-centered and student-centered technology-enhanced learning Environments. Science Education, 91, 727-749.

Zhang, J., Scardamalia, M., Lamon, M., Messina, R., \& Reeve, R. (2007). Socio-cognitive dynamics of knowledge building in the work of 9- and 10-year-olds. Educational Technology Research \& Development, 55, 117-145. 